\title{
2章 Computer Vision meets Fashion
}

\section{山口光太 ${ }^{\dagger}$}

キーワード : コンピュータビジョン, 画像認識, ファッション, Street-to-shop, トレンド分析, スタイル生成

\section{1.まえがき}

機械学習の応用が拡大するにつれ，ファッション分野で もコンピュータビジョンの適用が広がりを見せている.

AmazonはIoTデバイスによるパーソナルスタイリスト サービスを発表し*1，またEC活用などを目指し数多くの スタートアップ企業 (Fashwell, Wide Eyes, VASILY) が ファッション画像の認識をコアにしたデータ分析や検索 サービス開発を進めている。ファッション業界のマーケッ トは全世界で 3 兆ドル規模にも達し*2, コンピュータビ ジョンや機械学習による技術革新が大きな影響をもたらす 産業分野でもある.日本国内でも機械学習コンペが開催さ れるなど*3, 学術研究の面からも近年はファッションを題 材にしたものが数多く見られるようになり, 国際会議 KDDやICCVでもファッションを題材にしたワークショッ プが開催されるなど研究分野の進展も著しい* $4 * 5$. 本稿で は著者がこれまでに取組んできた事例を含めて研究課題を 解説し今後の展望について述べる.

\section{2.これまでの研究動向}

\section{1 衣服の画像認識}

コンピュータビジョンが取り扱う最も基本的なファッ ション認識の問題が衣服の種類の認識 (Clothing recognition) である.これは与えられた画像についてどの ような衣服であるのかを自動で判別するもので, 基本的な 衣服のカテゴリー(トップス，パンッ，スカート）の他にV V ネック, フレアスカートといった細部のパーツやスタイル の分類は属性認識 (Attribute Recognition) として取り扱わ れている1) 3). 衣服の画像認識は一般的な物体認識に比べ, 対象物の見た目が身体の姿勢に応じて変形し, 色や模様な

*1 Amazon Echo Look
*2 fashionunited.com
*3 https://deepanalytics.jp/compe/36
*4 KDD 2017 workshop: Machine Learning meets Fashion
*5 ICCV 2017 workshop: Computer Vision For Fashion
†株式会社サイバーエージェント
"Computer Vision meets Fashion" by Kota Yamaguchi (CyberAgent,
Inc., Tokyo)

760 (18)

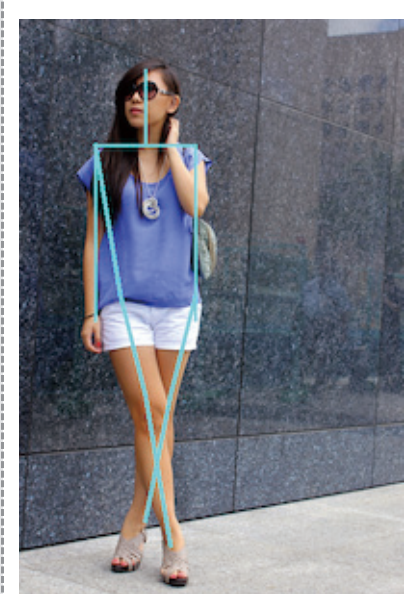

(a) 姿勢推定

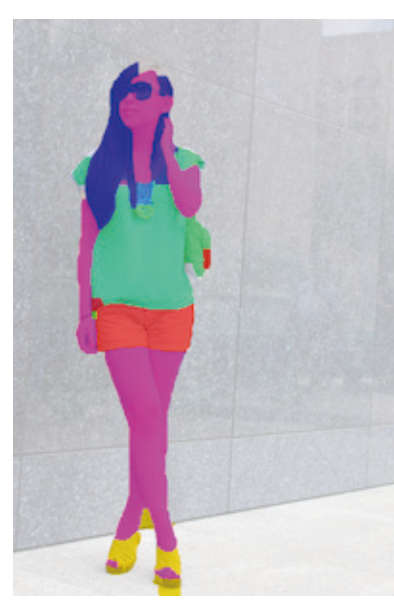

(b) 領域分割
図 1 衣服の認識は身体の姿勢と密接に関わる

著者らの手法6)では姿勢推定結果 (a) を条件入力としてセグメンテー ション(b)を求めている.

ども同じカテゴリーでもさまざまであることが挙げられ る. 例えば, 同じスカートという分類でも花柄のフレアス カートと黄色のマキシスカートでは見た目が大きく異な る. 衣服に関する研究で古くは上半身の衣服の形状の分類 や ${ }^{4)}$, 変形する衣服の構造を And-Orグラフで記述するモ デリング方法などが提案されていた5).

著者らは 2012 年に, 変形する衣服形状をセグメンテー ションによって認識する試みを発表した ${ }^{6)}$ 。この研究では 身体構造と衣服の着用部位に着目し, 人物の姿勢認識を 行った結果を条件入力とする画像のセグメンテーション問 題として定式化し, 確率的推論によって解く手法を提案し ている. セグメンテーションはその後もさまざまな研究が 提案されており7) 12), 特に近年では深層学習モデルを用 いた高速で性能の高いセグメンテーションモデルが見られ るようになっている13) 〜15).

\subsection{Street-to-Shop とカタログ検索}

画像を使ったファッション認識応用の中でも実用に結び つきが強いものがStreet-to-Shop検索だろう。これはユーザ がモバイル機器で撮影したストリートのスナップ写真から 


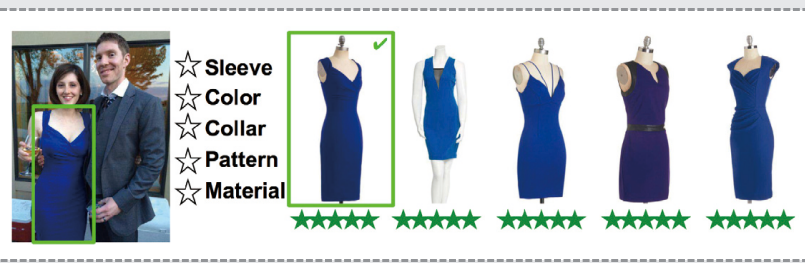

図2 Street-to-shop検索

左のスナップ写真に写る青いドレスとまったく同一の商品をECサイ トから検索する

同じECサイトのショップ商品を検索するというもので，姿 勢の推定を元に特徵量を抽出する手法16) や深層学習モデル を用いて類似度の計算を一貫して行う手法 ${ }^{17) か ゙ こ れ ま て ゙ に ~}$ も提案されている (図2)。また，ECサイトでのユーザ体験 を向上させることを目的に，カタログの商品を形状などの 細かい属性によってインタラクティブに並べ換える手法 ${ }^{18)}$ も試みられている．最近では属性の一部を書換えた商品の 検索を可能にするモデルも提案されている19).

\section{3 スタイルの認識とリコメンデーション}

個別の衣服の認識に対して全体の組合せ (Style, Outfit)の 認識も試みられている。例えば，文献20)では衣服の組合せや ソーシャルメディアのプロファイル情報から Fashionability をスコアとして導き出し，ユーザへの助言を行うパーソナ ルアシスタントを目指した手法を提案している，衣服の組 合せ全体が醸し出すスタイルはそもそも明確な定義が難し く, 教師データを用意することが難しい，そのため, 著者 らは文献21) でスタイルの定義を言語によるタグ付けではな く，あるスタイルについて順位付けをしたデータを元にスタ イルを構成する要素を分析するというアプローチを取ってい る. ファッションスタイルについてYes/Noで判別すること が難しい場合でも，写真を見比べるとどちらがより Goth ス タイルかといった判別を人は行いやすいためである22).

文献23)では順位付けを持つ弱教師デー夕から深層学習モ デルによりファッションに適した特徵量表現を学習する手 法を提案している.

\section{4 ファッションの意味構造}

衣服のカテゴリーや色などの単純な視覚的要素とスタイ ルのような抽象化された要素の間にどのような関係がある のかといった問いに対し，近年ではデー夕主導で分析する 試みが見られるようになってきた。文献24)では画像を用い ずに言語情報を用いて色などの低レベルな概念とスタイル のような高レベルな概念との間にどのような関係が成り立 つのか，翻訳モデルを用いて相互の関係を分析している.

衣服の組合せに関しても，二つのアイテムがマッチする かという関係性をデータから学習する試みが見られる. 文 献25)では衣服のペアについて相性が良いか悪いかを，大規 模な購買データを元に深層学習モデルで予測する手法を提 案している．文献26)では衣服の組合せに関して衣服の部位
の相互間の相性を分析し, 組合せができるもの, できない ものの関係をマイニングするアプローチを提案している. 著者らは全身の衣服の組合せや属性すべてを予測するモデ ルについて，CNNの予測結果から相互の関係性を同時確率 により組込んだ予測手法を提案している27).

\section{5 弱教師データからの属性認識}

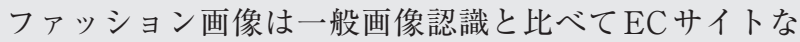
どの実応用に直接的に結びついており，学術研究も実環境 を想定したノイズのあるWebデータを用いた研究が行われ てきた ${ }^{28)}$ ．学術用に利用できるデータセットも Webデー 夕をクロールした弱教師データ 20) 27) が主体であるが，最近 ではクラウドソーシングを活用してWebデー夕に大規模な アトリビュートのアノテーションを施したDeepFashion データセットも公開され3)，深層学習モデルの学習に利用 されている299.

明示的なアノテーションが行われていない弱教師デー夕 から，教師データを発見するというアプローチもこれまで に提案されている，文献30)では，商品デー夕と一緒に表出 するキーワードの可視性をスコアとして求めてキーワード が学習可能な概念であるか判別し，また画像中での位置も 求めるという手法を提案している. 著者らはこの考え方を 発展させ, 深層学習モデルの内部発火を用いて可視性を導 く手法を提案した31) (図3).

\section{6 トレンド分析}

アパレル業界では，ファッションショーから始まるトレ ンドをいち早く取り入れつつ季節ごとの商品をデザインす る.このトレンドの分析は，ファッションについて梁い知 識と経験を持つ専門家が担ってきたが，これを機械学習に よって再現する試みが始まっている，文献32)では身体の各 部位についてパッチ特徴量をクラスタリングすることで ショー単位でのトレンドの分析を試みている．著者らは文 献33)で過去のファッションショーに現れたスタイルと,

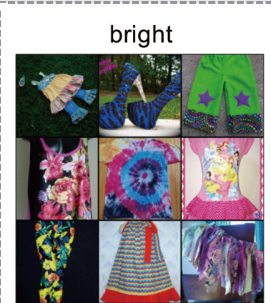

NOT bright

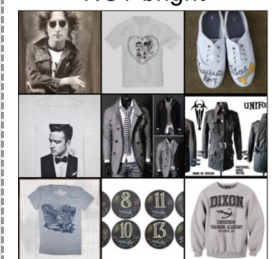

図3 データから画像で判別可能なキーワードを検出る

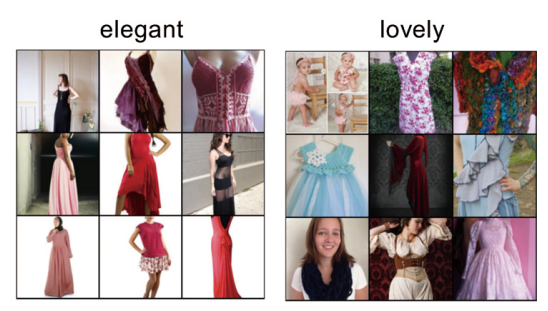

NOT elegant

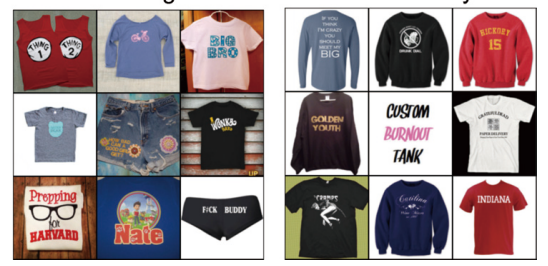




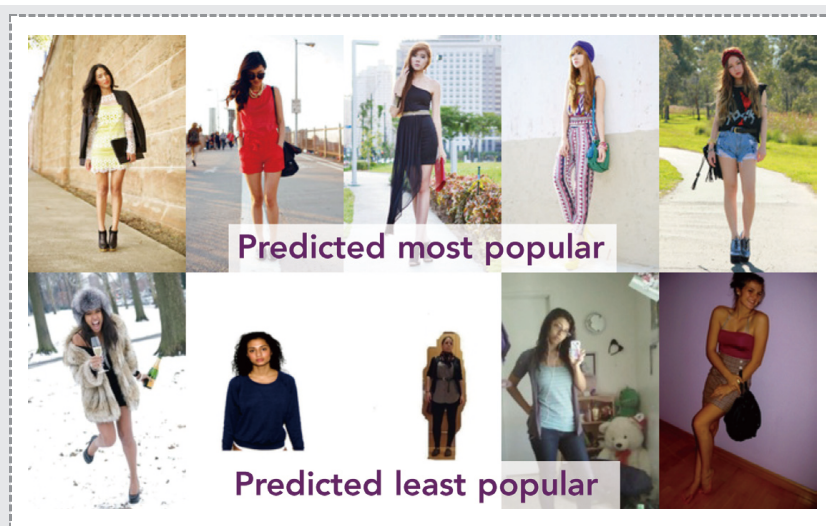

図4 クリック数の予測 38 )

画像の品質やユーザプロファイルにより人気度は影響される。

ソーシャルメディアに掲載されるスナップ写真との間の類 似性を学習することで, 特定のスタイルについてストリー トでの人気の分析を行った。文献 ${ }^{34)}$ では全世界のファッ ショントレンドの時系列分析を提案し, またそのための大 規模なデータセットを収集している．最近ではファッショ ントレンドが将来どのように変遷するかを予測する手法も 提案されている35).

\section{7 ユーザ行動の理解}

コンピュータビジョンを用いた視覚的な分析に加え, 推 薦などの実応用にはユーザ行動の理解も不可欠である。こ の方面から，ユーザの行動データを用いたマッチするアイ テムの予測と推薦手法がこれまでに提案されている25) 36). また, 文献37)ではユーザの好みを反映したランキング関数 を推定する手法を提案している.

人の行動データを取り入れた分析に関し, 著者らはソー シャルメディア上でのファッション画像の人気度を予測す るタスクに取組んでいる ${ }^{38)}$ 。具体的には, ファッションブ ログChictopiaにおいて画像やタグなどのコンテンッ要因 や友人数などのソーシャル要因からユーザクリック数を回 帰分析し, 統計的にどのような要因がクリック数に影響し ているのか分析した (図4). 結果からは極めて強いソー シャル要因の影響が示唆されている.ファッション画像の 品質については文献28)でもさまざまな要因を使った分析を 行っている.

\section{8 スタイルの生成}

明示的なアノテーションが存在しないデータから学習す ることができる深層学習手法としてGenerative Adversarial Networks (GAN) が注目を浴びているが, ファッション分野でも GANをはじめとする生成モデルの 研究が見られるようになっている. 文献39)では, 衣服を着 用したスナップ写真からカタログにあるような商品のみの 画像を条件付き GANにより生成するという試みを報告し ている，文献40)では，セグメンテーション結果に条件付き Variational Auto Encoderでスタイル付けを行うという手
法で，衣服を着用した人物画像を生成している，文献41)で は, 姿勢を条件入力として異なる画像の人物を別の姿勢で 再描画するモデルを提案している。スタイルの生成は ヴァーチャルフィッティングに直接応用でき, 今後も高品 質な生成手法が提案されることが期待される.

\section{3. 今後の展望}

高性能な深層学習モデルの普及とそのための大規模学習 データの出現により, 衣服の画像認識技術はすでにビジネ ス課題を実現する段階に来ている。どのように画像認識を 解決するかという基本的な研究課題から, 画像認識ができ るとしてどのような新たな問題を解き価值を生み出すかと いう点に研究の主軸が移ると予想される.

ファッション応用について，コンピュータビジョンや機 械学習は言葉に明示できない概念を計量するッールとして 機能する．例えば，「フォーマルさ」のような概念を言語に よって定義し, 手動で画像特徴量を設計して画一的な基準 で認識することはほとんど不可能である。デー夕主導の ファッション分析により，このような定義の難しい概念を Webのビッグデータから統計的に学習し定量化することが 可能となった. また, 定量化された概念を他の分野の問題 に適用することが可能になり，例えば，ファッションに関 するソーシャルメディアやECサイトの分析, ファッショ ントレンドの定量分析が実現可能となった．見た目に関す る, 必ずしも言葉にできない概念さえも定量化, 言語化し, 計量を可能にすることこそが，ファッション分野にコン ピュータビジョンがもたらす革新の本質である.

今後もコンピュータビジョン，機械学習を活用した ファッションに関する研究が現れると想定されるが，デー 夕主導の研究が成功するか否かを分ける鍵は学習デー夕を どう設計するかという点が大きい. 例えば，「原宿系」のよ うな指標を計量するようなモデルを学習するデー夕を集め るとすると, Yes/Noの絶対的な判断データを人に聞いて 収集すること困難である。しかし，2枚の画像の比較のよ うな方法では判断がつく場合もある。また，あらゆるボ キャブラリーについての辞書のようなデータセットを構築 することは不可能であるが，どういった語彙が学習可能で あるかをビッグデータから自動で判別するような手法であ れば，人手を最小限にして学習デー夕を構築することがで きる可能性がある.これからも新しいファッション応用に ついてデータの収集から活用手法まで見据えた研究が進展 することを期待している.

(2017年6月 15 日受付)

\section{〔文 献〕}

1) Chen, H., Gallagher, A. and Girod, B.: "Describing clothing by semantic attributes", ECCV, pp.609-623 (2012)

2) Chen, Q., Huang, J., Feris, R., Brown, L. M., Dong, J. and Yan, S.: "Deep Domain Adaptation for Describing People Based on FineGrained Clothing Attributes", CVPR, pp.5315-5324 (2015) 
3) Liu, Z., Luo, P., Qiu, S., Wang, X. and Tang, X.: "Deep-Fashion: Powering Robust Clothes Recognition and Retrieval with Rich Annotations", CVPR, pp.1096-1104 (2016)

4) Borras, A., Tous, F., Llado -s, J. and Vanrell, M.: "High-level clothes description based on colour-texture and structural features", Pattern Recognition and Image Analysis, pp.108-116 (2003)

5) Chen, H., Xu, Z. J., Liu, Z.Q. and Zhu, S. C.: "Composite templates for cloth modeling and sketching", CVPR, pp.943-950 (2006)

6) Yamaguchi, K., Kiapour, M. H., Ortiz, L.E. and Berg, T. L.: "Parsing clothing in fashion photographs", CVPR, pp.3570-3577 (2012)

7) Dong, J., Chen, Q., Xia, W., Huang, Z. and Yan, S.: "A deformable mixture parsing model with parselets", ICCV, pp.3408-3415 (2013)

8) Liu, S., Feng, J., Domokos, C., Xu, H., Huang, J., Hu, Z. and Yan, S.: "Fashion parsing with weak color-category labels", IEEE Transactions on Multimedia, 16, 1, pp.253-265 (2014)

9) Liu, S., Liang, X., Liu, L., Lu, K., Lin, L. and Yan, S.: "Fashion Parsing with Video Context", ACM Multimedia, 17, 8, pp.467-476 (2014)

10) Simo-serra, E., Fidler, S., Moreno-noguer, F. and Urtasun, R.: "A High Performance CRF Model for Clothes Parsing", ACCV, pp.2-11 (2014)

11) Yang, W., Luo, P. and Lin, L.: "Clothing co-parsing by joint image segmentation and labeling", CVPR, No.2013, pp.3182-3189 (2014)

12) Yamaguchi, K., Kiapour, M. H., Ortiz, L.E. and Berg, T. L.: "Retrieving similar styles to parse clothing", TPAMI, 37, 5, pp.10281040 (2015)

13) Liang, X., Shen, X., Yang, J., Liu, S., Tang, J., Lin, L. and Yan, S.: "Human Parsing with Contextualized Convolutional Neural Network", ICCV (2015)

14) Liang, X., Liu, S., Shen, X., Yang, J., Liu, L., Dong, J., Lin, L. and Yan, S.: "Deep Human Parsing with Active Template Regression", TPAMI, 37, 12, pp.2402-2414 (2015)

15) Tangseng, P., Wu, Z. and Yamaguchi, K.: "Looking at Outfit to Parse Clothing", arXiv (2017)

16) Liu, S., Song, Z., Liu, G., Xu, C., Lu, H. and Yan, S.: "Street-to-shop: Cross-scenario clothing retrieval via parts alignment and auxiliary set", CVPR (2012)

17) Kiapour, M. H., Han, X., Lazebnik, S., Berg, A.C. and Berg, T. L.: "Where to Buy It: Matching Street Clothing Photos in Online Shops", ICCV, pp.3343-3351 (2015)

18) Kovashka, A., Parikh, D. and Grauman, K.: "Whittle-search: Image search with relative attribute feedback", CVPR, pp.2973-2980 (2012)

19) Zhao, B., Feng, J., Wu, X. and Yan, S.: "Memory-Augmented Attribute Manipulation Networks for Interactive Fashion Search", CVPR (2017)

20)Simo-serra, E., Fidler, S., Moreno-noguer, F., Urtasun, R. and Rob, I. D.: "Neuroaesthetics in Fashion: Modeling the Perception of Fashionability", CVPR (2015)

21) Kiapour, M. H., Yamaguchi, K., Berg, A.C. and Berg, T. L.: "Hipster wars: Discovering elements of fashion styles", ECCV, pp.472-488 (2014)

22) Parikh, D. And Grauman, K.: "Relative attributes", ICCV, pp.503-510 (2011)

23) Simo-Serra, E. And Ishikawa, H.: "Fashion Style in 128 Floats: Joint Ranking and Classification Using Weak Data for Feature Extraction", CVPR, pp.298-307 (2016)
24) Vaccaro, K., Shivakumar, S., Ding, Z., Karahalios, K. and Kumar, R. "The Elements of Fashion Style", UIST (2016)

25) Veit, A., Kovacs, B., Bell, S., McAuley, J., Bala, K. and Belongie, S.: "Learning Visual Clothing Style with Heterogeneous Dyadic Cooccurrences", ICCV (2015)

26) Oramas, J. And Tuytelaars, T.: "Modeling Visual Compatibility through Hierarchical Mid-level Elements", arXiv:1604.00036v1 (2016)

27) Yamaguchi, K., Okatani, T., Sudo, K., Murasaki, K. and Taniguchi, Y.: "Mix and Match: "Joint Model for Clothing and Attribute Recognition", BMVC (2015)

28) Bossard, L., Dantone, M., Leistner, C., Wengert, C., Quack, T. and Van Gool, L.: "Apparel classification with style", ACCV, pp.321-335 (2012)

29) Liu, Z., Yan, S., Luo, P., Wang, X. and Tang, X.: "Fashion Landmark Detection in the Wild", ECCV (2016)

30) Berg, T. L., Berg, A.C. and Shih, J.: "Automatic attribute discovery and characterization from noisy web data", ECCV, pp.663-676 (2010)

31) Vittayakorn, S., Umeda, T., Murasaki, K., Sudo, K., Okatani, T. and Yamaguchi, K.: "Automatic Attribute Discovery with Neural Activations", ECCV (2016)

32) Hidayati, S. C., Hua, K.-L., Cheng, W.-H. and Sun, S.-W.: "What are the fashion trends in new york-", ACM Multimedia, pp.197-200, ACM (2014)

33) Vittayakorn, S., Yamaguchi, K., Berg, A.C. and Berg, T. L.: "Runway to realway: Visual analysis of fashion", WACV, pp.951-958 (2015)

34) Abe, K., Suzuki, T., Ueta, S., Nakamura, A., Satoh, Y. and Kataoka, H.: "Changing Fashion Cultures", arXiv (2017)

35) Al-Halah, Z., Stiefelhagen, R. and Grauman, K.: "Fashion Forward: Forecasting Visual Style in Fashion", arXiv (2017)

36) McAuley, J., Targett, C., Shi, Q. and Hengel, A.v. d.: "Image-based Recommendations on Styles and Substitutes", SIGIR (2015)

37) He, R. And McAuley, J.: "Ups and Downs: "Modeling the Visual Evolution of Fashion Trends with One-Class Collaborative Filtering", WWW, pp.507-517 (2016)

38) Yamaguchi, K., Berg, T.L. and Ortiz, L. E.: "Chic or Social: "Visual Popularity Analysis in Online Fashion Networks", ACM Multimedia, pp.773-776 (2014)

39) Yoo, D., Kim, N., Park, S., Paek, A.S. and Kweon, I. S.: "Pixel-Level Domain Transfer", ECCV (2016)

40) Lassner, C., Pons-Moll, G. and Gehler, P. V.: "A Generative Model of People in Clothing", arXiv (2017)

41) Ma, L., Jia, X., Sun, Q., Schiele, B., Tuytelaars, T. and Van Gool, L. "Pose Guided Person Image Generation", arXiv (2017)

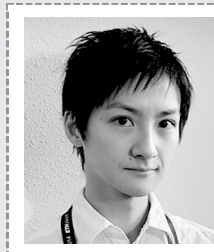

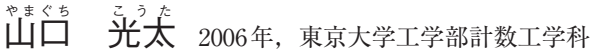
卒業. 2008年, 東京大学情報理工学系研究科修士課程 修了. 2014年, Stony Brook大学コンピュータ科学の Ph.D.取得. 2017 年まで, 東北大学情報科学研究科助 教. 現在, (株) サイバーエージェント AI Lab研究員. 2015 年，2016年，2017 年，MIRU優秀賞受賞. CVF， IPSJ, IEICE 各会員. 